Chapman, E. M., and Maloof, F. (1955). Medicine (Baltimore), 34, 261. Curran, R., Eckert, H., and Wilson, G. M. (1958). F. Path. Bact., 76, 541.

Doniach, I. (1958). Brit. med. Bull., 14, 181.

Eckert, H., Green, M., Kilpatrick, R., and Wilson, G. M. (1960). Clin. Sci., 20, 87.

Goudie, R. B., Anderson, J. R., and Gray, K. G. (1959). F. Path. Bact., 77, 389.

Green, M., Fisher, M., Miller, H., and Wilson, G. M. (1961). Brit. med. f., 2, 210.

Greene, R. (1950). 7. Endocr., 7, 1.

Irvine, W. J., Macgregor, A. G., and Stuart, A. E. (1962). Lancet, 2, 843

Jones, K. H., and Fourman, P. (1963). Ibid., 2, 121.

Macgregor, A. G. (1963). The Thyroid and its Diseases, p. 19, edited by A. S. Mason. Pitman, London.
Riddell, V. (1962). Brit. 7. Surg., 49, 465.

Roitt, I. M., and Doniach, D. (1958). Lancet, 2, 1027

Rose, N. (1963). Ibid., 2, 116.

Schade, R. O. K., Owen, S. G., Smart, G. A., and Hall, R. (1960). J. clin. Path., 13, 499.

Segal, R. L., Silver, S., Yohalem, S. B., and Feitelberg, S. (1961). Amer. f. Med., 31, 354 .

Sheline, G. E., and Miller, E. R. (1959). Arch. intern. Med., 103, 924.

Sheline, G. E., and Miller, E. R. (1959). Arch. intern. Med., 103, 924.

Thorén, A., and Wijnbladh, H. (1956). Acta endocr. (Kbh.), 22, 224.
Volpe, R., Schatz, D. L., Scott, A., Peller, J. A., Vale, J. M., Ezrin, C., and Johnston, M. W. (1960). Canad. med. Ass. f., 83, 1407.

Wayne, E. J. (1954). Brit. med. F., 1, 411.

Werner, S. C., Coelho, B., and Quimby, E. H. (1957). Bull. N.Y. Acad. Med., 33, 783.

Whitesell, F. B., and Black, B. M. (1949). f. clin. Endocr., 9, 1202.

Williams, E. D., and Doniach, I. (1962). F. Path. Bact., 83, 255.

\title{
Chromosome Studies During Early and Terminal Chronic Myeloid Leukaemia
}

\author{
N. H. KEMP,* M.B., B.S.; J. L. STAFFORD, м.B., CH.B.; ROSEMARY TANNER, B.SC.
}

Brit. med. F., 1964, 1, 1010-1014

The presence of the Philadelphia chromosome $\left(\mathrm{Ph}^{1}\right)$ is invariably associated with chronic myeloid leukaemia (Baikie et al., 1960 ; Nowell and Hungerford, 1960a, 1960b, 1961 ; Tough et al., 1961, 1962, 1963 ; Sandberg et al., 1962b; Fitzgerald et al., 1963), although its absence is probably not sufficient evidence to deny this diagnosis (Tough et al., 1963). As all the patients so far reported had haematologically and, usually, clinically apparent leukaemia when the chromosome studies were first performed, the timing of the appearance of $\mathrm{Ph}^{1}+$ cells, in relation to the initiation of the disease process, remains undefined.

The purpose of this communication is to demonstrate that $\mathrm{Ph}^{1}+$ cells are present before the disease is even haematologically obvious and to stress the value of early definitive diagnosis whereby treatment might be started before conventional haematological criteria are available. We report the findings from one patient in whom $\mathrm{Ph}^{1}+$ cells were observed before there was any haematological or clinical evidence of the leukaemia but who subsequently developed chronic myeloid leukaemia which rapidly progressed into an acute phase: a terminal myeloblastic proliferation was associated with further chromosome abnormalities. Also reported are the findings from four patients who presented as problems of diagnosis and in whom $\mathrm{Ph}^{1}+$ cells were observed before the disease had become fully manifest. None of these cases had received antileukaemic treatment when they were first studied. Case 1 was studied during an investigation of the chromosome complement of bone-marrow oells from patients with polycythaemia vera, and the initial findings have been reported elsewhere (Kemp et al., 1961).

\section{Methods}

Although examination of bone-marrow specimens by a "direct" method is preferable for the cytogenetic study of primary bone-marrow disease, it is not always practicable, especially with serial studies, for, as in Case 1, repeated marrow aspiration is not well tolerated by certain patients. So long as the leukaemic cells are circulating, and if every attempt is made to harvest them when they are dividing, peripheral blood specimens have, in our laboratory, proved more informative

^ From the Haematology Department, St. George's Hospital, London. than has been the experience of certain other workers (Sandberg et al., 1962a). The peripheral blood leucocytes were cultured by a modification of the technique of Moorhead et al. (1960), aliquots being harvested at regular intervals from the time when each specimen was first set up in order to make available for study any cells that divided during the early periods of culture but not subsequently; these would be missed if the cultures were not terminated until the conventional 48 hours or more had elapsed. When possible, leucocyte cultures with and without phytohaemagglutinin were studied in parallel. Exclusion of phytohaemagglutinin from the cultures prevents contamination with metaphases from transformed lymphocytes and permits any divisions that are seen to be attributed more confidently to an abnormal cell population present in the inoculum. The leucocytes from several specimens were set up in fresh homologous plasma as well as in autologous plasma, the former on occasion providing a more active culture.

Both short-term cultures (Ford et al., 1958) and a "direct" method (Tjio and Whang, 1962) have been used for the study of bone-marrow specimens, the final preparations of either blood or marrow being made by air-drying. As is the practice with other workers, we have assessed the presence or absence of the $\mathrm{Ph}^{1}$ chromosome only in cells in which all the small acrocentric chromosomes have been clearly defined.

Histochemical assessment of the polymorphonuclear neutrophil leucocyte alkaline phosphatase (L.A.P.) content was performed on peripheral blood specimens, using the modified azodye coupling technique and scoring method described by Hayhoe and Quaglino (1958).

\section{Case 1}

The patient was a man aged 39 in 1959 . Polycythaemia rubra vera was first diagnosed in March 1959, when albuminuria, noted when he was undergoing treatment for chronic eczema, was being investigated. The findings at this time were: haemoglobin $(\mathbf{H b})$ 19.4 g. $/ 100 \mathrm{ml}$.; packed-cell volume (P.C.V.) $59 \%$; white-cell count (W.B.C.) $25,200 /$ c.mm. (neutrophils $68 \%$, lymphocytes $25 \%$, monocytes $7 \%$ ); platelets $486,000 /$ c.mm.

The patient was effectively treated, initially by venesection; later, in addition, he received three injections each of $5 \mathrm{mc}$. of ${ }^{32} \mathrm{P}$. The haematological findings in this patient from the time of diagnosis until death are shown in Fig. 1. 
In May 1959, during an attack of right lobar pneumonia, the W.B.C. rose to $50,000 / \mathrm{c} . \mathrm{mm}$., which included occasional myelocytes and metamyelocytes. However, when the infection was successfully treated the total leucocyte count returned to its previous level of approximately 20,000/c.mm., and immature granulocytes disappeared from the blood. During the course of the polycythaemia, and particularly after ${ }^{32} \mathrm{P}$ treatment, the patient suffered from attacks of gout; these were treated with probenecid, colchicine, and phenylbutazone-a total of $5.4 \mathrm{~g}$. of the latter being given for this purpose between February 1960 and November 1961.

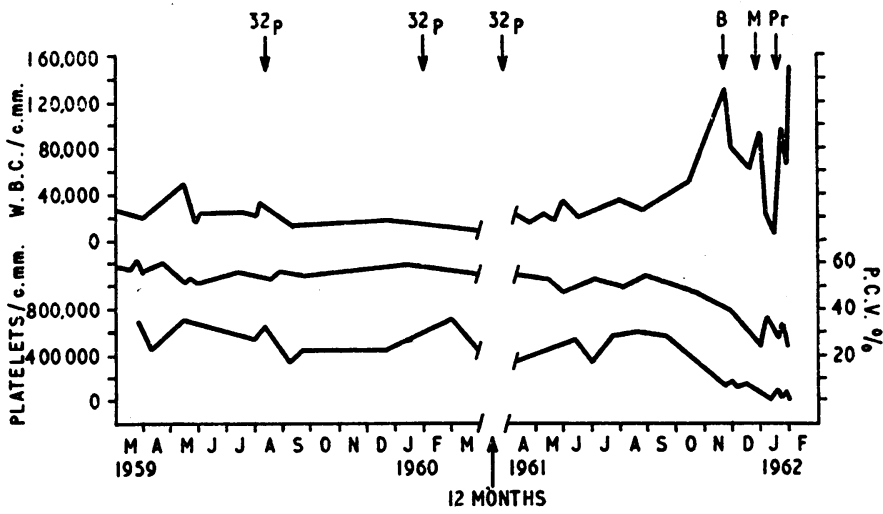

Fig. 1.-Case 1. Showing changes of packed cell volume, white blood cells, and platelet count from time of diagnosis. $B=$ Busulphan. $M=$ Mercaptopurine. $\operatorname{Pr}=$ Prednisone.

Chromosome studies were first performed on a specimen of bonemarrow taken in April 1961, at which time the peripheral blood picture was unexceptional for polycythaemia rubra vera. The results of this and subsequent chromosome investigations, together with the relevant haematological findings, are recorded in Table I.

The patient's progress was followed at frequent intervals, but there was little change until September 1961, when the W.B.C. rose rapidly and was accompanied by a fall in the Hb, P.C.V., and platelet count (Fig. 1). Neutrophil metamyelocytes, myelocytes, and eventually promyelocytes and occasional myeloblasts appeared in the blood, the W.B.C. reaching $132,000 / \mathrm{c} . \mathrm{mm}$. The picture was that of chronic myeloid leukaemia, and treatment with busulphan (6 mg. daily) was started on 20 November; this reduced the number of white cells circulating, including granulocyte precursors, but had little effect on the promyelocytes and blast cells. By the end of December 1961 the clinical and haematological picture had changed to that of a myeloblastic phase of chronic myeloid leukaemia: mercaptopurine (100 mg. daily) was given from 22 December in addition to the busulphan. By this treatment the W.B.C. was reduced to $3,800 /$ c.mm. but the circulation of blast cells persisted.

When, because of severe thrombocytopenia, treatment had to be abandoned on 4 January 1962 after a total of $192 \mathrm{mg}$. of busulphan and $1.3 \mathrm{~g}$. of mercaptopurine had been given, the W.B.C. rose rapidly to $153,000 /$ c.mm. with myeloblasts and promyelocytes as the predominant cells. Despite prednisone $(10 \mathrm{mg}$. t.d.s.) the patient died three weeks later with severe haemorrhagic manifestations of the then persistent thrombocytopenia. This was two-and-threequarter years after the polycythaemia was initially diagnosed and four months after the leukaemic process first became evident in the peripheral blood.

\section{Chromosome Analysis}

The chromosome numbers of cells from a series of specimens are presented, with the relevant haematological data, in Table I, together with the incidence of the Philadelphia chromosome in the various cell lines.

The first specimen of bone-marrow (A), taken during the study of a series of patients with polycythaemia rubra vera (Kemp et al., 1961), contained cells with the normal number of 46 chromosomes. However, in all the cells suitable for assessment, with an otherwise normal male karyotype, a chromosome indistinguishable from the $\mathbf{P h}^{1}$ was noted (Fig. 2). The possibility that chronic myeloid leukaemia might be developing in this patient was supported by the low neutrophil L.A.P. score of 6 , although at this time the other haematological values were unexceptional for polycythaemia rubra vera.

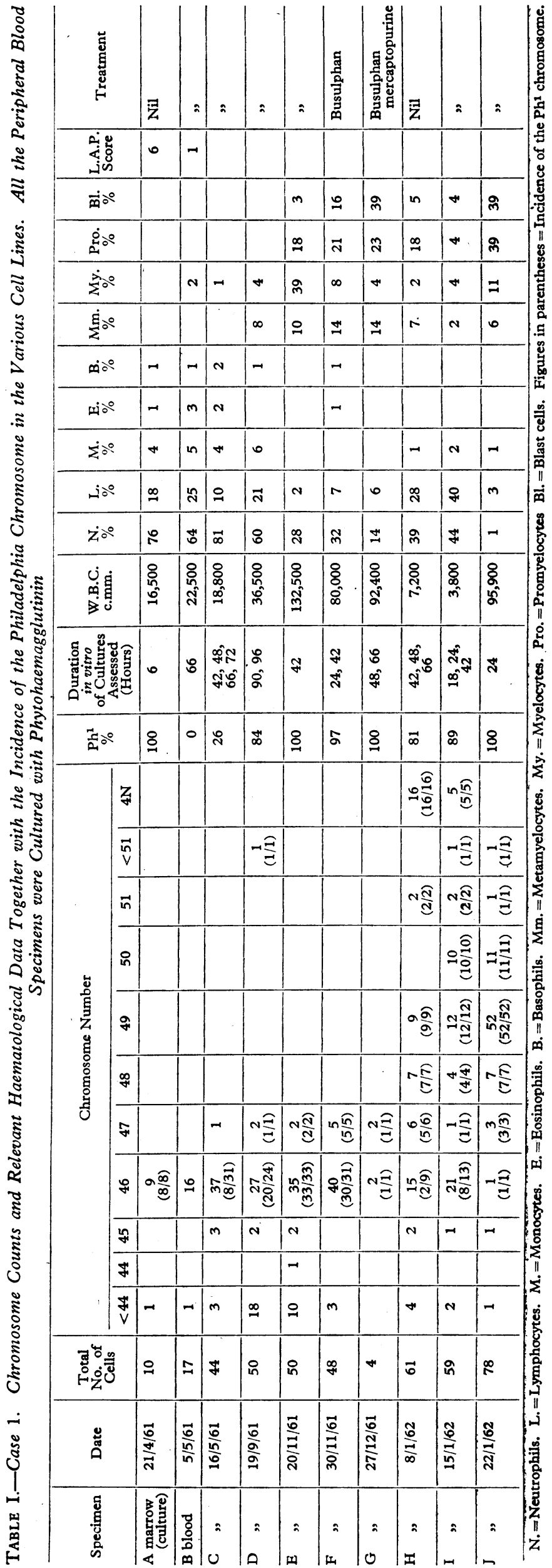


All the cells of the blood specimen B, taken two weeks after the bone-marrow, were $\mathrm{Ph}^{1}-$, and it was only when myelocytes began to circulate that $\mathrm{Ph}^{1}+$ cells were detected in the blood (C and D). The percentage of $\mathrm{Ph}^{1}+$ cells increased as more immature granulocytes circulated until, in November 1961, when the blood was typical of chronic myeloid leukaemia, all the assessable cells contained the $\mathrm{Ph}^{1}$ chromosomes (E). In subsequent specimens all the cells with 46 or more chromosomes were $\mathrm{Ph}^{1}+$ except in cultures $\mathrm{H}$ and $\mathrm{I}$, when some $\mathrm{Ph}^{1}-$ cells were observed. As these cells with a normal male karyotype were mostly present in the cultures that were harvested after 48 hours, they were considered to reflect the increased proportion of lymphoid cells present in these blood specimens at this time of relatively effective therapy due to mercaptopurine.

Initially the modal chromosome number of the marrow and blood specimens was 46 . However, when a significant number of blast cells started to circulate, the proportion of hyperdiploid cells increased. In culture $\mathrm{F}$ four of the five cells with 47 chromosomes had the same karyotype containing an extra chromosome No. 21 or 22 (Denver). Although very few satisfactory metaphases were obtained from culture $G$, those with 46 and 47 chromosomes were present in equal proportions.

Cultures $H$, I, and $J$, taken after busulphan and mercaptopurine treatment had been stopped, contained many hyperdiploid cells. Cells with 49 and 50 chromosomes were prominent in I, while those with 49 chromosomes dominated culture $\mathrm{J}$, which was established at the height of the terminal myeloblastic crisis. All the polyploid cells in $\mathbf{H}$ and $\mathbf{I}$ were $\mathrm{Ph}^{1}+$ and were approximately tetraploid.

Karyotypes of 79 of the hyperdiploid cells from the last three cultures showed that there was usually more than one cell line within the various modes, though in the last culture, J, most of the cells with 49 chromosomes had the same karyotype (Fig. 3). In all of the hyperdiploid cells the extra chromosomes were indistinguishable from the normal set except that many cells contained an additional small acrocentric identical with the $\mathrm{Ph}^{1}$. There were then two $\mathrm{Ph}^{1} s$ in most of the cells with 48 chromosomes and in all with more than 48. At least six chromosomes indistinguishable from a No. 3 , a 4 or 5 , a $6-12$, a 13-15, a 19-20, and a $\mathrm{Ph}^{1}$ were involved in the formation of the various interrelated cell lines. A simple system of successive nondysjunction is easily invoked, which would account for the presence of all the cell lines observed by a stepwise evolution from an original $46 \mathrm{Ph}^{1}+$ cell.

\section{Case 2}

In September 1962 a raised W.B.C. was noted when the patient, a woman aged 24, was being followed-up after the surgical removal, in 1960, of a small fibroma of doubtful aetiology from her right forearm. She was well and there were no abnormal clinical findings ; the values were $\mathrm{Hb} 12.4 \mathrm{~g} . /$ 100 ml.; W.B.C. 24,000/c.mm. (neutrophils $60 \%$, lymphocytes $25 \%$, monocytes $7 \%$, eosinophils $8 \%$ ). The leucocytosis persisted, and one month later, when the marrow showed increased granulopoietic activity, a few myelocytes and metamyelocytes were circulating.

Chromosome studies were performed in November 1962, when the W.B.C. was $48,000 / \mathrm{c} . \mathrm{mm}$. The findings are recorded in Table II. The W.B.C. continued to rise and was associated with a slight anaemia. In April 1963 the blood picture was $\mathrm{Hb} 10.4 \mathrm{~g} . / 100$ ml.; W.B.C. 95,000/c.mm. (neutrophils $56 \%$, lymphocytes $3 \%$, monocytes
Fig. 3.- Case 1. Karyotype of cell line with 49 chromosomes from peripheral blood culture (J) showing two $\mathrm{Ph}^{1}$ chromosomes and two extra large chromosomes. The relatively poor chromosome morphology was characteristic of the aneuploid cells in cultures $\mathrm{H}$, I, and J. 
$2 \%$, eosinophils $8 \%$, neutrophil myelocytes $17 \%$, metamyelocytes $10 \%$, promyelocytes $3 \%$, blasts $1 \%$ ); 1 nucleated red cell/ 100 white cells. The patient, apart from slight tiredness, remains well and has not so far received antileukaemic treatment. There are still no abnormal clinical findings and the spleen has never been palpably enlarged.

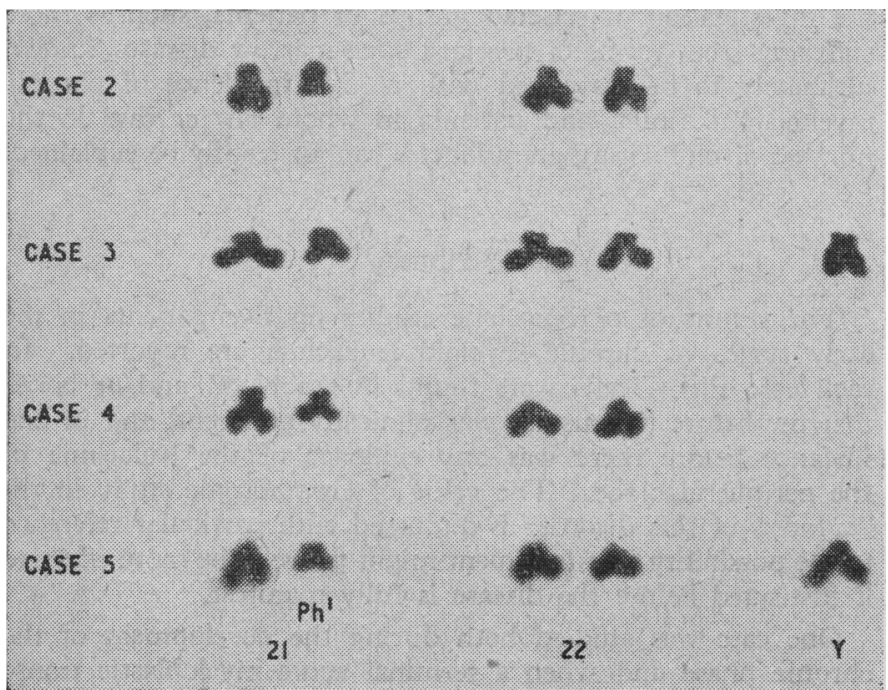

Frg. 4. - Cases 2-5. Chromosomes 21, 22, and $\mathrm{Y}$ showing the $\mathrm{Ph}^{1}$ chromosome.

\section{Case 3}

A male Ghanaian aged 41 in 1962 attended hospital in October 1961 for investigation of a periostitis of the left tibia, having had pain and some swelling of the ankle over the previous 10 years. A raised W.B.C. was recorded early in 1962, when the findings were $\mathrm{Hb} 12$ g. $/ 100 \mathrm{ml}$; W.B.C. $26,400 /$ c.mm. (neutrophils $51 \%$, lymphocytes $8 \%$, monocytes $2 \%$, metamyelocytes $19 \%$, myelocytes $19 \%$, blasts $1 \%$ ) ; 2 nucleated red cells $/ 100$ white cells. The bonemarrow at this time was very cellular and showed increased granulopoiesis.

The results of the chromosome studies performed in February 1962 , when the blood picture was substantially unchanged, are shown in Table II. When the patient was last seen in April 1962 there were no abnormal clinical findings other than those related to the periostitis. A more recent follow-up has not been possible.

\section{Case 4}

This patient, a woman aged 27 in 1962, was admitted to hospital in December 1962 with acute lower abdominal pain. Laparotomy revealed a haemoperitoneum due to bleeding from a ruptured cyst in each ovary ; these were oversown. Haemostasis proved difficult throughout the operation and the post-operative period was complicated by a haematoma in the abdominal wall. A blood count on the day after the operation showed a severe leucocytosis: $\mathrm{Hb}$ 8.8 g. $/ 100 \mathrm{ml}$. ; W.B.C. $110,000 / \mathrm{c} . \mathrm{mm}$. (neutrophils $82 \%$, lymphocytes $6 \%$, monocytes $2 \%$, metamyelocytes $6 \%$, neutrophil myelocytes $4 \%)$; 1 nucleated red cell $/ 100$ white cells ; platelets $726,000 / \mathrm{c} . \mathrm{mm}$. The W.B.C. was still between 60,000 and $100,000 /$ c.mm. when chromosome studies were carried out on two specimens of blood, one taken five days and the other 20 days post-operatively. The findings are given in Table II.

A satisfactory haematological remission was obtained by treatment with busulphan started on 25 December 1962. At no stage of the illness has there been any enlargement of the spleen, liver, or lymph nodes.

\section{Case 5}

A raised W.B.C. was noted when this patient, a man aged 61 in 1963, was admitted to hospital in March 1963 with incipient gangrene of the left foot. The findings were: $\mathrm{Hb} 12.3 \mathrm{~g} . / 100 \mathrm{ml}$. ; W.B.C. $51,000 /$ c.mm. (neutrophils $62 \%$, lymphocytes $6 \%$, monocytes $2 \%$, eosinophils $2 \%$, basophils $2 \%$, metamyelocytes $7 \%$, neutrophil myelocytes $15 \%$, promyelocytes $2 \%$, blasts $2 \%$ ); 3 nucleated red cells $/ 100$ white cells; platelets $382,000 /$ c.mm. when the initial chromosome studies were performed (Table II). Despite a left lumbar sympathectomy (15 March) the peripheral vascular disease progressed, necessitating a below-knee amputation of the left leg (22 March) from which recovery was uneventful.

$X$-ray therapy to the splenic region produced a satisfactory haematological remission, but the patient was readmitted in May with a right hemiplegia, and despite temporary improvement died on 31 May 1963, when he collapsed with severe abdominal pain. Necropsy revealed widespread atheroma with cerebral, splenic, and pulmonary infarction; small-bowel obstruction with perforation and a localized abscess and leukaemic infiltration of the spleen, liver, and bone-marrow.

\section{Discussion}

Not only is the presence of the Philadelphia chromosome in the leukaemic cells in most instances of chronic myeloid leukaemia well established, but it appears to be specific for this disorder as it has not been found in the blood or bone-marrow of patients suffering from other forms of leukaemia or primary bone-marrow disease (Baikie et al., 1961 ; Hungerford, 1961 ; Hungerford and Nowell, 1962 ; Kemp et al., 1963 ; Nowell and Hungerford, 1962 ; Sandberg et al., 1962b). Before the exact relation between this disease and its chromosome abnormality can be understood, certain problems remain unresolved. Among these is the probability that in $\mathrm{Ph}^{1}+$ cases not only the myeloid cells but also the erythroid and megakaryocyte series in the marrow are $\mathrm{Ph}^{1}+$ (Tough et al., 1963), and, secondly, the occurrence of the rare case of otherwise typical chronic myeloid leukaemia in which the $\mathrm{Ph}^{\mathbf{1}}$ chromosome cannot be detected in the blood or marrow cells despite exhaustive searching (Tough et al., 1963). Little is known about the timing of the appearance of $\mathrm{Ph}^{1}+$ cells in relation to the development of the disease, and it is with this problem in mind that the present series is reported.

The findings from Case 1 clearly illustrate that $\mathrm{Ph}^{1}+$ cells are already present in the bone-marrow before there is any evidence of a leukaemic process in the peripheral blood and that the emergence of these $\mathrm{Ph}^{1}+$ cells into the circulation coincides with the appearance of granulocyte precursors and the development of the typical blood picture. In each of the present cases $\mathrm{Ph}^{1}+$ cells were observed in the marrow and/or

TABLE II.-Cases 2-5. Chromosome Counts and Relevant Haematological Data

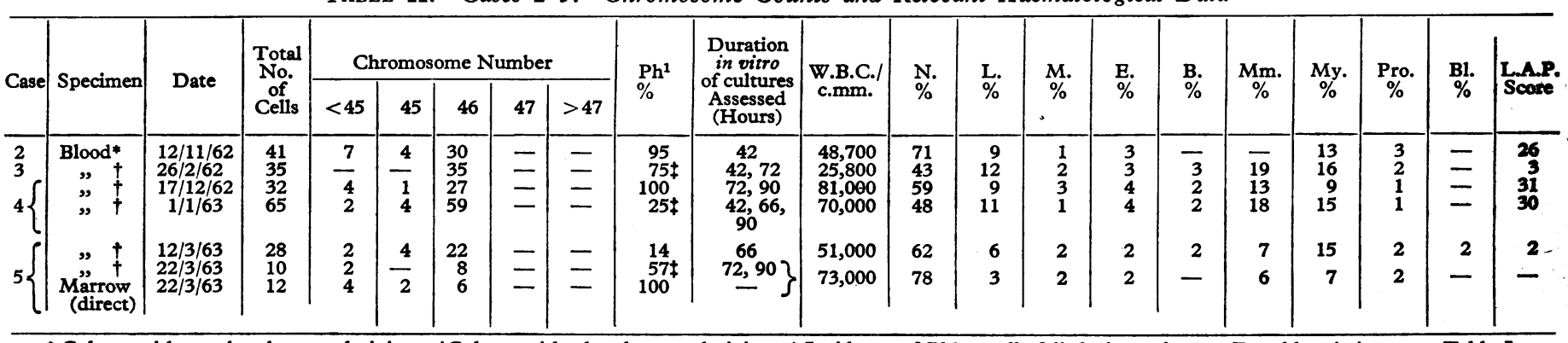


blood during the initial stages of the disease, when no clinical manifestation was apparent and when the haematological findings were equivocal.

The ultimate development of the typical leukaemic bloodpicture in Cases 1 and 2 illustrates the inevitability of the progressive proliferation of these $\mathrm{Ph}^{1}+$ cells and underlines their diagnostic importance when found in the blood or marrow of an individual without any other evidence of the disease. The value of cytogenetic studies in the diagnosis of either early or equivocal chronic myeloid leukaemia is greater than that of the assessment of L.A.P. activity ; for although in three of the present cases the L.A.P. score was of the very low levels characteristic of chronic myeloid leukaemia, in two cases it was within the normal range. It is of interest that in these two cases the distribution of alkaline phosphatase activity was atypical, there being more cells with scores of 2 and even 3 than would be expected from normal blood with a similar total L.A.P. score. That this may reflect a reaction to leukaemic cells by normal myeloid cells in the earlier stages of the disease is suggested by the occurrence of one $\mathrm{Ph}^{1}-$ cell in the leucocyte cultures without phytohaemagglutinin in Case 2.

Sandberg et al. (1962b) have suggested that the occasional subjects with chronic myeloid leukremia lacking the $\mathrm{Ph}^{1}$ chromosome may be patients with a leukaemic picture complicating polycythaemia vera, while Wahrman et al. (1962) refer to the possibility that cases of chronic myeloid leukaemia following polycythaemia vera might represent a special leukaemic entity with its own chromosomal characterization. In Case 1 our findings lend support to neither of these possibilities, while the absence of anything like the manifold chromosome abnormalities described by Wahrman et al. (1962) supports the contention that these were the result of the extensive irradiation received by their patient (Court Brown et al., 1962).

The hyperdiploid $\mathrm{Ph}^{1}+$ cell lines observed in Case 1 during the development of the acute phase are thought to represent the blast-cell population which, incidentally, was noted to divide earlier in vitro (within 21 hours) than the myelocytes (approximately 48 hours) which had been circulating during the chronic phase. Although initially cells with a range of karyotypes were produced, all probably derived from the $46 \mathrm{Ph}^{1}+$ chronic myeloid cells, in the final stages of the acute phase one cell line became dominant. This sequence of events suggests the type of mechanism by which the established aneuploid cell lines reported in some patients with acute leukaemia (Baikie et al., 1961 ; Ford, 1961 ; Sandberg et al., 1961, 1962a ; Tough et al., 1961, 1963 ; Hungerford and Nowell, 1962), either arising de novo or following chronic myeloid leukaemia, have been selected. In this laboratory a comparable sequence of events has been observed during the early stages of the development of a stemcell leukaemia. That the final cell-line in Case 1 should contain 49 chromosomes is of interest in view of other reported instances in which cells with the same chromosome number have predominated (Tough et al., 1961 ; F. J. W. Lewis, personal communication, 1963). The persistence of the $\mathrm{Ph}^{1}$ chromosome in the blast cells during the acute phase contrasts with the findings of Nowell and Hungerford (1961).

The consistent occurrence of aneuploidy coincided with treatment by alkylating agents and antimetabolites, but, although the possibility cannot be excluded that these chemicals may indirectly have influenced the chromosomal stability of the $46 \mathrm{Ph}^{1}+$ cells, it seems unlikely that the changes were the direct result of their action. Such changes have not been found in other patients receiving these drugs; the aneuploidy occurred only in the $\mathrm{Ph}^{1}+$ cells, all the $\mathrm{Ph}^{1}$ - cells in cultures $\mathrm{H}$ and I possessing the normal male karyotype, and, furthermore, structural abnormalities reported to have been induced by alkylating agents (Conen and Lansky, 1961) such as dicentrics and fragments, were not seen in any of the aneuploid cells.

In the present state of our knowledge of the earliest stages of leukaemia it is possible that the control of chronic myeloid leukaemia would be more effective if treatment could be started before the disease process is haematologically fully manifest. Apart from providing additional and fundamental information about the leukaemic cell, chromosome study is currently the only means of achieving a definitive diagnosis during these early stages. Such cases might most profitably be sought by the investigation of selected groups of patients, such as those suffering from forms of primary bone-marrow diseases, known ultimately to be associated with a high incidence of chronic myeloid leukaemia, and patients in whom an increase in the number of circulating granulocytes cannot readily be explained.

\section{Summary}

The results of chromosome studies on five patients in the early stages of chronic myeloid leukaemia are reported. In each case $\mathrm{Ph}^{1}+$ cells were found in the blood and/or bonemarrow before the disease was clinically apparent, and in one instance before there was any evidence of the leukaemia in the peripheral blood. The value of chromosome study in the diagnosis of this disorder is discussed with particular reference to the possibility that treatment might prove to be more effective if instituted before the disease is fully manifest.

One case was studied both during the development of the chronic phase and when a terminal acute myeloblastic transformation supervened. Initially, the latter was associated with the appearance of hyperdiploid $\mathrm{Ph}^{1}+$ cells with as many as 52 chromosomes, although a $49 \mathrm{Ph}^{1}+$ cell line dominated the final stages. The possible significance of these findings is discussed.

We are grateful to Dr. T. R. E. Pilkington, Mr. R. Cox, Dr. A. L. Jacobs, Mr. G. Westbury, Dr. K. A. Newton, Professor H. Ellis, and Dr. J. G. Humble for permission to study these patients while under their care. Miss P. Carr and Miss E. Carman provided expert technical assistance. We also acknowledge the financial support of the British Empire Cancer Campaign and the Leukaemia Society Inc., so enabling this work to be carried out.

\section{REFERENCES}

Baikie, A. G., Court Brown, W. M., Buckton, K. E., Harnden, D. G. Jacobs, P. A., and Tough, I. M. (1960). Nature (Lond.), 1.8, 1165. Jacobs, P. A., McBride, J. A., and Tough, I. M. (1961). Brit. med. f., 1, 1564 .

Conen, P. E., and Lansky, G. S. (1961). Ibid., 2, 1055.

Court Brown, W. M., Jacobs, P. A., Tough, I. M., and Bailde, A. G. (1962). Lancet, 1, 1242.

Fitzgerald, P. H., Adams, A., and Gunz, F. W. (1963). Blood, 21, 183.

Ford, C. E. (1961). Proc. 8th Congr. Europ. Soc. Haemat. Vienna, 1, 104.

Jacobs, P. A., and Lajtha, L. G. (1958). Nature (Lond.), 181, 1565.

Hayhoe, F. G. J., and Quaglino, D. (1958). Brit. F. Haemat., 4, 375.

Hungerford, D. A. (1961). F. nat. Cancer Inst., 27, 983.

- and Nowell, P. C. (1962). Ibid., 29, 545.

Kemp, N. H., Stafford, J. L., and Tanner, R. K. (1961). Proc. 8th Congr. Europ. Soc. Haemat., Vienna, 1, 92.

- (1963). Unpublished observations.

Moorhead, P. S., Nowell, P. C., Mellman, W. J., Battips, D. M., and Hungerford, D. A. (1960). Exp. Cell. Res., $20,613$.

Nowell, P. C., and Hungerford, D. A. (1960a). Science, 132, 1497.

- (1960b). \%. nat. Cancer Inst., 25, 85

(1961). Ibid., 27, 1013.

(1962). Ibid., 29, 911.

Sandberg, A. A., Ishihara, T., Crosswhite, L. H., Hauschka, T. S. (1962a). Cancer Res., 22, 748.

Miwa, T., and Hauschka, T. S. (1961)

Cancer Res., 21, 678.

Tiio, J. H., and Whang, J. (1962). Stain Technol., 37, 17.

Tough, I. M., Court Brown, W. M., Baikie, A. G., Buckton, K. E., Harnden, D. G., Jacobs, P. A., King, M. J., and McBride, J. A. (1961). Lancet, 1, 411.

- - - and Williams, J. A. (1962). Ibid., 2, 115

Jacobs, P. A., Court Brown,

Wahrman, J., Schaap, T., and Robinson, E. (1962). Ibid., 1, 1698. 